\title{
Photochemistry of hematite photoanodes under zero applied bias
}

\author{
Timothy L. Shelton, Nicholas Harvey, Jiarui Wang, Frank E. Osterloh* \\ Department of Chemistry, University of California, One Shields Avenue, Davis, CA, 95616 \\ KEYWORDS Photocatalysis, Water Splitting, Surface Photovoltage Spectroscopy, Hole trap, Built-in voltage
}

\begin{abstract}
Surface photovoltage spectroscopy (SPS) was used to observe photochemical charge separation and oxidation reactions on $\mathrm{Fe}_{2} \mathrm{O}_{3}$ nanorod arrays under zero applied bias. Nanorod films were grown from $\mathrm{FeCl}_{3}$ under hydrothermal conditions followed by calcination at $550^{\circ} \mathrm{C}$. A negative photovoltage of up $-130 \mathrm{mV}$ is observed under $2.0-4.5 \mathrm{eV}\left(0.1 \mathrm{~mW} \mathrm{~cm} \mathrm{~m}^{-2}\right)$ illumination, confirming $2.0 \mathrm{eV}$ as the effective bandgap of the material, and electrons as majority carriers. SPS in the presence of air, nitrogen, water, oxygen, and under vacuum suggest that the photovoltage is associated with the oxidation of surface water and with reversible surface hole trapping on the 1 min time scale and de-trapping on the $1 \mathrm{~h}$ time scale. $\mathrm{O}_{2}$ promotes water oxidation by increasing the concentration of surface holes. Sacrificial donors $\mathrm{KI}, \mathrm{H}_{2} \mathrm{O}_{2}$ or potassium hydroxide increases the voltage to -240 and $-400 \mathrm{mV}$, due to improved hole transfer. Cobalt oxide and Co-Pi cocatalysts quench the voltage, which is tentatively attributed to the removal of surface states and enhanced e/h recombination. An energy diagram is used to relate the experimental photovoltage to the built-in potentials at the respective interfaces.
\end{abstract}

\section{Introduction}

Hematite photoelectrodes are among the best examples for the successful implementation of the nanoscaling strategy to improve performance for solar water splitting. ${ }^{1-10}$ By making the dimensions of the light absorber equal to the minority carrier diffusion length, short-lived holes can be extracted and used for water oxidation. As the concentration and mobility of charge carriers for metal oxides is several orders of magnitude below that of doped II-VI, III-V, or group V semiconductors, the space charge layers/electric fields that form at the interface are much weaker, and do not strongly affect charge separation. Also, the electric field in nanostructured photoelectrodes is strongly screened by electrolytes. Charge separation in nanoscale absorbers can be improved through surface modifications with electrocatalysts, charge selective contacts, and recombination resistant materials. ${ }^{11}$ For example, Dunwei Wang's group has shown that the photovoltage of $\mathrm{Fe}_{2} \mathrm{O}_{3}$ can be raised by surface recrystallization ${ }^{12}$ or by the addition of $\mathrm{NiO}$ overlayers. ${ }^{13}$ Higher photovoltage can be also be achieved with $\mathrm{Co}-\mathrm{Pi},{ }^{14} \mathrm{RuO}_{2}{ }^{15}$ or cobalt oxide coatings ${ }^{16-18}$ whereas $\mathrm{n}-\mathrm{SnO}_{2},{ }^{19} \mathrm{n}-\mathrm{Ga}_{2} \mathrm{O}_{5},{ }^{20} \mathrm{Nb}_{2} \mathrm{O}_{5}{ }^{21}$ or $\mathrm{Al}_{2} \mathrm{O}_{5}{ }^{22-24}$ underor photoanodes increase the photocurrent of $\mathrm{Fe}_{2} \mathrm{O}_{3}$. However, the reason for the improvement is often not clear. For example, Co-Pi and $\mathrm{NiO}$ speed up the water oxidation kinetics and they are also thought to aid e/h separation at the interface. ${ }^{13,14}$ ${ }^{25,}{ }^{26}$ Similarly, diamagnetic metal oxide coatings are believed to simultaneously quench recombination sites and promote selective charge transfer. ${ }^{19-24}$ Photoelectrochemistry is not able to resolve the kinetic and thermodynamic contributions because the measured current and photopotentials are the result of coupled charge transfer at solid-solid and solid-liquid interfaces. ${ }^{27}$ Thus any changes in the photopotential across an absorber films could be the result of a change in majority carrier transport through a film (affects Ohmic drop), due to a change of the electrochemical overpotentials, a new built-in junction, or changes in the electrochemical double layer in front of the electrode.

As we show here, some of these shortcomings can be overcome with Surface Photovoltage Spectroscopy (SPS). SPS is a contactless technique that probes Contact Potential Difference changes $(\triangle \mathrm{CPD})$ in light absorbing films in response to excitation with spectrally resolved light (Figure 1). ${ }^{28,29}$ For example, migration of negative charge towards the Kelvin probe leads to a negative voltage. Because even small displacements $(10 \mathrm{~nm})$ of charge carrier concentrations $\left(10^{10}\right.$ per $\left.\mathrm{cm}^{2}\right)$ can yield potentials on the $\mathrm{mV}$ scale, the sensitivity of the method is much higher than that of photoelectrochemistry. ${ }^{30}$ Due to the low current, losses from overpotentials and ohmic potential drops are insignificant, and since no electrolyte is used, electrochemical double layer effects can be excluded. This makes SPS particularly useful to probe intrinsic charge transfer processes in nanostructured light absorbing materials. ${ }^{31-36}$ 
Here we apply the technique to thin films of $\mathrm{Fe}_{2} \mathrm{O}_{3}$ nanorods grown onto FTO. We find that the photovoltage of the material is very sensitive to the ambient environment in the chamber and to any surface treatment of the films. This provides support for the earlier observation of the importance of surface states in hematite for hole trapping and water oxidation. ${ }^{37-39}$ The data shows that $\mathrm{Fe}_{2} \mathrm{O}_{3}$ can oxidize a variety of compounds under zero applied electrochemical bias, and that oxygen promotes the oxidative ability. These findings are relevant to the understanding of the photochemistry of hematite and to its optimization as a photoanode.

\section{Results and Discussion}

$\mathrm{Fe}_{2} \mathrm{O}_{3}$ nanorod arrays (Figure 2) were fabricated by hydrothermal synthesis followed by calcination, according to the method by Vayssieres. ${ }^{9}$ The films exhibit the characteristic rod morphology reported previously in the literature. ${ }^{3,9,10} \mathrm{X}$ ray diffraction of the annealed film confirms that the rods crystallize in the hematite structure type (Figure 2C). A profilometry scan for a film synthesized over a $24 \mathrm{~h}$ period is shown in Figure 2D. The average thickness of the film is 520 $\mathrm{nm}$, which can be taken as the approximate nanorod length. Figure 3 shows SPV and diffuse reflectance optical spectra of a $\mathrm{Fe}_{2} \mathrm{O}_{3}$ nanorod array film exposed to air atmosphere. The onset of the photovoltage coincides with the indirect band gap absorption at $2.0 \mathrm{eV}$, close to the reported band gap of the material. $^{3}$ The absence of sub-gap signals indicates that the material is free of mid-gap defect states. ${ }^{40}$ Also, no significant signal variation is observed at $2.5 \mathrm{eV}$, even though an earlier resonant inelastic $\mathrm{x}$-ray scattering study had postulated a quantum size confinement effect in the $\mathrm{Fe}_{2} \mathrm{O}_{3}$ nanorod arrays. ${ }^{41}$ The measured photovoltage is negative, indicating that it is due to majority (electron) carrier movement towards the substrate, as shown in Figure 1, and as previously observed for other n-type nanocrystals, incl. $\mathrm{BiVO}_{4}{ }^{35}$ and $\mathrm{HCa}_{2} \mathrm{Nb}_{3} \mathrm{O}_{10} .{ }^{40}$

The photovoltage reaches its most negative value of $-140 \mathrm{mV}$ at a photon energy $2.75 \mathrm{eV}$, in a region of strong visible absorbance. To determine the extent to which the photovoltage is limited by the film thickness, SPV spectra were recorded for $\mathrm{Fe}_{2} \mathrm{O}_{3}$ arrays synthesized over 1, 3, 6, and 24 hour periods. In these samples, the film thickness varies between 67 and 520 $\mathrm{nm}$, as determined with profilometry (data not shown). From Figure 4 , it can be seen that the photovoltage increases with film thickness (the lower voltage for the $200 \mathrm{~nm}$ film is due to statistical variation). Also, it can be seen that the photovoltage maximum shifts from $3.75 \mathrm{eV}$ for the thinnest film to $2.75 \mathrm{eV}$ for the thicker films, close to the optical absorbance maximum in Figure 3. This suggests that the photovoltage is limited by light absorption in the films. Indeed, based on the published absorption coefficient $\alpha=8 \times 10^{6} \mathrm{~m}^{-1}$ at $2.75 \mathrm{eV}$ for a hematite nanorod film, ${ }^{3}$ absorption of $99 \%$ of all $2.75 \mathrm{eV}$ photons requires a $575 \mathrm{~nm}$ thick film, close to the thickest films observed here. This confirms that light absorption is a limiting factor for the photovoltage of the films.
To investigate the effect of surface chemistry on the photovoltage, SPV scans were recorded for $\mathrm{Fe}_{2} \mathrm{O}_{3}$ films exposed to vacuum, air, nitrogen, and water saturated nitrogen atmosphere, as shown in Figure 5. Interestingly, the strong SPV signal in air disappears almost completely when the $\mathrm{Fe}_{2} \mathrm{O}_{3}$ film is exposed to vacuum $\left(10^{-4} \mathrm{mBar}\right)$ for an hour. Admission of $99 \%$ pure $\mathrm{N}_{2}$ gas to a vacuum-dried film restores $18-21 \%$, of the original photovoltage, depending on the photon energy (2.7 and $3.6 \mathrm{eV}$ respectively), while the addition of saturated water vapor in nitrogen or of pure oxygen leads to $70 \%$ recovery of the signal. When pure $\mathrm{O}_{2}$ is introduced to a $\mathrm{Fe}_{2} \mathrm{O}_{3}$ film without the vacuum drying step, the photovoltage increases to $115 \%$ of the value in air and to $1750 \%$ of the vacuum value. This demonstrates the strong effect of water and oxygen on the ability of the $\mathrm{Fe}_{2} \mathrm{O}_{3}$ nanorod film to separate charge.

In principle, the gas-dependence of the photovoltage could be due to changes of the band bending in $\mathrm{Fe}_{2} \mathrm{O}_{3}$ in response to the formation of new surface states, as observed with a silicon photoelectrode. ${ }^{33}$ However, time dependent measurements (below) show that the photovoltage signal recovery with $\mathrm{Fe}_{2} \mathrm{O}_{3}$ is slow $(0.5 \mathrm{~h})$ and therefore more likely associated with chemical reactions of photoholes. Reactions 2 and 4 are possibilities, although complete water oxidation according to Eq. 4 normally requires applied bias of $>0.6 \mathrm{~V} \mathrm{RHE}$ with $\mathrm{Fe}_{2} \mathrm{O}_{3}{ }^{13}$ Because of that reaction 2 is more likely. The positive effect of oxygen on the photovoltage size could be related to its ability to accept photoelectrons from $\mathrm{Fe}_{2} \mathrm{O}_{3}$ according to Eq. 3, forming superoxide. ${ }^{42}$ The resulting increase in surface hole concentration would then facilitate water oxidation according to equation 2 .

$$
\begin{array}{ll}
\text { 1. } & \mathrm{hv} \rightarrow \mathrm{e}^{-}+\mathrm{h}^{+} \\
\text {2. } & \mathrm{h}^{+}+\mathrm{H}_{2} \mathrm{O} \rightarrow \mathrm{OH} \bullet+\mathrm{H}^{+} \\
\text {3. } & \mathrm{e}^{-}+\mathrm{O}_{2} \rightarrow \mathrm{O}_{2}^{-} \\
\text {4. } & 4 \mathrm{~h}^{+}+2 \mathrm{H}_{2} \mathrm{O}+\rightarrow \mathrm{O}_{2}+4 \mathrm{H}^{+}
\end{array}
$$

A synergistic interaction between oxygen and $\mathrm{H}_{2} \mathrm{O}$ oxidation has been previously hypothesized in nano- $\mathrm{TiO}_{2}$ photoelectrodes, on the basis of time resolved absorption measurements. ${ }^{43}$ Furthermore, for $\mathrm{Fe}_{2} \mathrm{O}_{3}$, oxygen plays a role in acetaldehyde degradation. ${ }^{44}$ To further investigate the role of surface-adsorbed water on the photovoltage, a $\mathrm{Fe}_{2} \mathrm{O}_{3}$ film sample was scanned repeatedly every $24 \mathrm{~h}$ under $1.0 \mathrm{~atm}$ of air in a sealed chamber (Figure 6A). It can be seen that the measured photovoltage is reduced with each scan from initially -85 $\mathrm{mV}$ to $-70 \mathrm{mV}$ and then to $-65 \mathrm{mV}$. When the sample was removed from the chamber, rinsed thoroughly with water, dried in air and retested, the photovoltage increased to -100 $\mathrm{mV}, 118 \%$ of the initial value. These observations support the conclusion that slow water oxidation occurs according to equations 2. The gradual decay of the photovoltage in subsequent scans would then be due to build-up of protons and hy- 
droxyl groups on the $\mathrm{Fe}_{2} \mathrm{O}_{3}$ surface. Interestingly, there is a slow reversible component to the photovoltage (Figure 6B): When the light is turned off after an initial $0.6 \mathrm{~h}$ illumination period, about $20 \%$ of the initial photovoltage $(-0.225 \mathrm{~V})$ decays over the course of 30 minutes. Additional on/off cycles (Figure 5C) performed over a $6 \mathrm{~h}$ period, show that the reversible portion amounts to about $75-125 \mathrm{mV}$, or $50 \%$ of the initial value in Figure 6B. The slow time scale of the signal recovery rules out photochemical charge separation inside a space charge layer, which should occur much faster. Instead we assign this reversible voltage component to deep hole trapping at surface Fe-OH sites, according to equation 2. Reversible hole trapping in surface states has been previously observed with impedance spectroscopy by Klahr et al. ${ }^{37,38}$ and independently by Cummings et al. ${ }^{39}$ These surface states are involved in water oxidation and are believed to consist of either hydroxyl radicals or $\mathrm{Fe}(>3+)$ species. These states are also likely responsible for the Fermi pinning effect in $\mathrm{Fe}_{2} \mathrm{O}_{3}$, as discussed by Thorne et al. in a recent paper. ${ }^{27}$ As expected, the oxidizing surface states generated in illuminated $\mathrm{Fe}_{2} \mathrm{O}_{3}$ films have the ability to oxidize a variety of electron donors. SPV spectra of $\mathrm{Fe}_{2} \mathrm{O}_{3}$ films treated with $0.01 \mathrm{M} \mathrm{KI}$ solution and $1 \% / \mathrm{wt}$. hydrogen peroxide solution in water are shown in Figure 7A. It can be seen that while KI treatment has little effect on spectral shape, it increases the maximum photovoltage to $-240 \mathrm{mV}$, $185 \%$ of the untreated film in air.

Similarly, $\mathrm{H}_{2} \mathrm{O}_{2}$ treatment induces a photovoltage of $-400 \mathrm{mV}$, a $307 \%$ increase over the untreated film. These effects can be explained with photochemical oxidation of iodide and hydrogen peroxide, according to equations 5 and $6 .{ }^{45,46}$

$$
\begin{array}{ll}
\text { 5. } & \mathrm{h}^{+}+\mathrm{I}^{-1 / 2} \mathrm{I}_{2} \\
\text { 6. } & 2 \mathrm{~h}^{+}+\mathrm{H}_{2} \mathrm{O}_{2} \rightarrow \mathrm{O}_{2}+2 \mathrm{H}^{+} \\
\text {7. } & \mathrm{h}^{+}+\mathrm{OH}^{-} \rightarrow \mathrm{OH} \bullet
\end{array}
$$

Interestingly, the photoonset with peroxide is shifted to $\sim 1.9$ $\mathrm{eV}$, indicating the formation of a new $\mathrm{Fe}(3+) \cdot\left(\mathrm{H}_{2} \mathrm{O}_{2}\right)$ surface state that can be directly excited with light (see discussion below).

Considering reactions 2, 3, 6 and 7, the charge separation dynamics in $\mathrm{Fe}_{2} \mathrm{O}_{3}$ are expected to depend strongly on the surface $\mathrm{pH}$. The effect of $\mathrm{pH}$ on the photoelectrochemistry of $\mathrm{Fe}_{2} \mathrm{O}_{3}$ was noted in 1974 by Allen Bard' s group. ${ }^{47}$ Below $\mathrm{pH}=4$, $\mathrm{Fe}_{2} \mathrm{O}_{3}$ is found to dissolve, while above this $\mathrm{pH}$ the water oxidation photoonset potential shifts negatively with $\mathrm{pH}$, due to variation of the flatband potential (Fermi energy) in $\mathrm{Fe}_{2} \mathrm{O}_{3}$. ${ }^{47}$.

${ }^{48}$ Indeed, SPV spectra in Figure 7B are also found to have a strong $\mathrm{pH}$-dependence. Reduced photovoltage values are seen for films treated with dilute acid solutions of $\mathrm{pH}=5,4$ and a fully quenched signal is observed at $\mathrm{pH}=1$. This is attributed to etching of the $\mathrm{Fe}_{2} \mathrm{O}_{3}$ surface and introduction of elec-

tron/hole recombination centers at the hematite surface. Raising the $\mathrm{pH}$ to 9 and 11 does not bring about notable change, but at $\mathrm{pH}=13$ the voltage at $2.75 \mathrm{eV}$ is increased to $-166 \mathrm{mV}$, i.e. $128 \%$ of the value for the as-prepared $\mathrm{Fe}_{2} \mathrm{O}_{3}$ film. This agrees with the fact that hydroxide is a better hole acceptor than water, based on thermodynamic and mechanistic considerations, ${ }^{49}$ and in agreement with improved photocurrents at high $\mathrm{pH}^{3}$ Lastly, we probe photovoltage spectra of cobalt oxide modified $\mathrm{Fe}_{2} \mathrm{O}_{3}$ films. Cobalt oxide coatings on $\mathrm{Fe}_{2} \mathrm{O}_{3}$ had been previously shown to increase the photovoltage by up to $80 \mathrm{mV} .{ }^{18,50}$ Interestingly, we find that for $\mathrm{Co}\left(\mathrm{NO}_{3}\right)_{2}$ treated and annealed films the photovoltage is completely quenched (Fig 8). The same is found for $\mathrm{Fe}_{2} \mathrm{O}_{3}$ films that were modified by electrodeposition of Co-Pi. ${ }^{51,52}$ The finding of photovoltage quenching contrasts with our previous observation that $\mathrm{Co}_{3} \mathrm{O}_{4}$ coatings on $\mathrm{BiVO}_{4}$ lead to a photovoltage boost. ${ }^{53}$ We hypothesize that the added cocatalyst layer interferes with the hole trap sites in untreated $\mathrm{Fe}_{2} \mathrm{O}_{3}$ films, ${ }^{37-39}$ thus quenching the photovoltage. Also, the $\mathrm{Co}_{2} \mathrm{O}_{3}$ conduction band edge ${ }^{53}$ is positive of that of $\mathrm{Fe}_{2} \mathrm{O}_{3}$, making hole transfer difficult based on thermodynamic reasons.

To further analyze the thermodynamics of the $\mathrm{FTO} / \mathrm{Fe}_{2} \mathrm{O}_{3} / \mathrm{L}$ system at pH 7 ( $\mathrm{L}=$ air, water, $\mathrm{KI}, \mathrm{H}_{2} \mathrm{O}_{2}$, vacuum, nitrogen) we construct the energy scheme in Figure 9. As can be seen from the diagram, the built in voltage at the $\mathrm{FTO} / \mathrm{Fe}_{2} \mathrm{O}_{3}$ interface $\left(\mathrm{E}_{\mathrm{CB}}-\mathrm{E}_{\mathrm{F}}\right)$ is very small. This explains the lack of a photovoltage of a dried $\mathrm{Fe}_{2} \mathrm{O}_{3}$ film in vacuum environment. Most of the photovoltage signal is generated by electron hole separation at the $\mathrm{Fe}_{2} \mathrm{O}_{3}$ surface. This occurs by either injection of holes into sacrificial electron donors $\left(\mathrm{KI}, \mathrm{H}_{2} \mathrm{O}_{2}, \mathrm{H}_{2} \mathrm{O}\right)$ or by reversible trapping into $\mathrm{Fe}_{2} \mathrm{O}_{3}$ surface states. The addition of Co-Pi or $\mathrm{CoO}_{x}$ cocatalysts completely quenches the photovoltage, either via removal of the surface traps or by reducing the hole lifetime. Overall, observed photovoltages for $\mathrm{Fe}_{2} \mathrm{O}_{3}$ represent one forth of the theoretical (thermodynamic) values. For example, the built-in potential of the $\mathrm{Fe}_{2} \mathrm{O}_{3}-\mathrm{H}_{2} \mathrm{O}_{2}$ contact is $\mathrm{V}_{\mathrm{bi}}=+2.4 \mathrm{~V}-0.27 \mathrm{~V}=+2.13 \mathrm{~V}$, while the observed photovoltage for $\mathrm{H}_{2} \mathrm{O}_{2}$ oxidation is $+0.4 \mathrm{~V}$ based on Figure 7A. The difference between the observed and expected signals is due to the low amount of $\mathrm{H}_{2} \mathrm{O}_{2}$ on the $\mathrm{Fe}_{2} \mathrm{O}_{3}$ film and due to the low hole concentration in the $\mathrm{Fe} 3 \mathrm{~d}$ band, under the 0.1 $\mathrm{mW} \mathrm{cm}^{-2}$ illumination conditions. Assuming the observed signal for hole trapping (75-125 $\mathrm{mV}$, i.e. reversible photovoltage component in Figure 5) is also four times lower than the built-in potential, the position of the surface trap sites can be estimated $0.3-0.5 \mathrm{~V}$ above the Fe $3 \mathrm{~d}$ band, as shown in Figure 9. This position is close to the hydroxyl reduction potential of $+2.02 \mathrm{~V}$ vs NHE in alkaline solution, ${ }^{54}$ suggesting trapping of holes is associated with the conversion of surface bound water/hydroxide into hydroxyl according to eq. 7 .

\section{Conclusion}


In conclusion we present the first quantitative SPV study on hematite films. A negative photovoltage of up $-130 \mathrm{mV}$ is observed under $2.0-4.5 \mathrm{eV}\left(0.1 \mathrm{~mW} \mathrm{~cm}^{-2}\right)$ illumination, confirming $2.0 \mathrm{eV}$ as the effective bandgap of the material and no detectable mid gap states. For thin films, the photovoltage is limited by light absorption and for thick films it is determined by the $\mathrm{Fe}_{2} \mathrm{O}_{3}$ surface chemistry. Under zero applied bias, the photochemistry of $\mathrm{Fe}_{2} \mathrm{O}_{3}$ nanorod arrays on FTO is dominated by hole injection into added sacrificial donors (iodide, water, and hydrogen peroxide) and by reversible hole trapping in surface states, likely involving hydroxyl groups. Quenching of the photovoltage by added $\mathrm{Co}-\mathrm{Pi}$ and $\mathrm{CoO}_{\mathrm{x}}$ cocatalysts is attributed to removal of surface bound water and/or shortened hole lifetimes. The quenching of the photovoltage under vacuum is due to removal of surface bound water. Oxygen is found to boost the photovoltage, which is attributed to its ability to stabilize photoholes at the $\mathrm{Fe}_{2} \mathrm{O}_{3}$ surface. High $\mathrm{pH}$ promotes the photovoltage because hydroxide oxidation is thermodynamically preferred over water oxidation. These findings confirm that photochemical charge separation at nanostructured $\mathrm{Fe}_{2} \mathrm{O}_{3}$ is mostly determined by the kinetics and thermodynamics at the surface.

\section{Experimental}

Chemicals: $\quad \mathrm{FeCl}_{3} * 6 \mathrm{H}_{2} \mathrm{O} \quad$ (Sigma Aldrich, 99.+\%), $\mathrm{Na}_{2} \mathrm{HPO}_{4} * 7 \mathrm{H}_{2} \mathrm{O}$ (Sigma Aldrich, 99.5\%), $\mathrm{NaIO}_{4}$ (Fischer Scientific, 99\%, recrystallized), cobalt(II) nitrate hexahydrate (98+\%, Aldrich), $\mathrm{NaOH}$ (Fischer Scientific, 99.9+\%), $\mathrm{NaNO}_{3}$ (Sigma Aldrich, 99\%), conc. (16N) $\mathrm{HNO}_{3}(\mathrm{aq})$ and $\mathrm{HCl}$ (aq) were obtained from Fischer Scientific and diluted as necessary. Water was purified to $18 \mathrm{M} \Omega \mathrm{cm}$ resistivity using a Nano-pure Infinity system. FTO coated glass slides used were Corning brand TEC-15.

Synthesis of electrodes: $\mathrm{Fe}_{2} \mathrm{O}_{3}$ films on FTO were prepared according to the method by Vayssieres. ${ }^{12 \mathrm{~h}}$ A FTO-coated glass slide $1 \times 2 \mathrm{~cm}^{2}$ was cleaned by subsequent sonication in acetone, methanol, and isopropanol followed by thorough rinsing in water. All but a $1 \mathrm{~cm}^{2}$ area was masked with Scotch tape placed in a Teflon-lined steel autoclave that contained 25 $\mathrm{mL}$ of a solution that was $0.15 \mathrm{M}$ in $\mathrm{FeCl}_{3} * 6 \mathrm{H}_{2} \mathrm{O}$ and $0.1 \mathrm{M}$ in $\mathrm{NaNO}_{3}$. The container was sealed and heated to $100^{\circ} \mathrm{C}$ for $1 \mathrm{~h}$. The FTO slide was removed, sonicated for $10 \mathrm{~s}$ in water, rinsed twice with water, and then calcined at $550^{\circ} \mathrm{C}$ for 1 hour. Thicker $\mathrm{Fe}_{2} \mathrm{O}_{3}$ films were grown by increasing the hydrothermal heating time to 3,6 , and 24 hours. For $\mathrm{pH}$ modification, $0.01 \mathrm{~mL}$ of $\mathrm{HNO}_{3}$ or $\mathrm{NaOH}$ adjusted to the desired $\mathrm{pH}$ by dilution from a $1 \mathrm{M}$ stock solution was dropped onto the electrodes, allowed to soak in for two minutes and then dried in a stream of nitrogen gas. $\mathrm{Co}_{3} \mathrm{O}_{4}$-modified $\mathrm{Fe}_{2} \mathrm{O}_{3}$ films were obtained by dropping $0.1 \mathrm{~mL}$ of $0.1 \mathrm{M}$ and $0.01 \mathrm{M} \mathrm{Co}\left(\mathrm{NO}_{3}\right)_{2}$ solutions on the $\mathrm{Fe}_{2} \mathrm{O}_{3}$ with followed by annealing at $550^{\circ} \mathrm{C}$ for two hours before SPV analysis. Diffuse reflectance UV/vis spectra were taken on as-prepared hematite films using a Thermo Scientific Evolution 220 Spectrometer. Surface photovoltage (SPS) measurements were performed under air atmosphere using a vibrating gold Kelvin probe $(3 \mathrm{~mm}$ diameter, Delta PHI Besocke) mounted inside a home-built vacuum chamber and a Kelvin control 07 (Delta PHI Besocke) with a sensitivity of $1 \mathrm{mV}$. The sample-probe distance was kept consistent (ca. $1 \mathrm{~mm}$ ). Hematite films were illuminated through the probe with monochromatic light from a $300 \mathrm{~W}$ Xe lamp filtered through an Oriel Cornerstone 130 monochromator (light intensity range: $0.1-0.3 \mathrm{~mW} / \mathrm{cm}^{2}$ ). For excitation spectrum see Wang et al. ${ }^{31}$ SPV spectra were corrected for drift by subtracting a dark background. Vacuum measurements were performed under $10^{-4}$ mbar. Controlled gas conditions were established by evacuating the chamber to $10^{-1}$ mbar and backfilling with either $\mathrm{N}_{2}, \mathrm{O}_{2}$, or water vapor in $\mathrm{N}_{2}$. This cycle was repeated twice. Water saturated $\mathrm{N}_{2}$ was prepared by storing nitrogen over water for one hour.

\section{AUTHOR INFORMATION}

\section{Corresponding Author}

Department of Chemistry, University of California, Davis. One Shields Avenue, Davis, CA, 95616, USA. Fax: (+1)530 752 8995; E-mail: fosterloh@ucdavis.edu

\section{Funding Sources}

We are grateful for financial support from Research Corporation for Science Advancement (Scialog award) and from the National Science Foundation (NSF, Grants 1152250 and 1464938).

\section{Figure Captions}

Figure 1. A) Measurement configuration of SPS. The sample film is illuminated through the semi-transparent Kelvin probe. Photovoltage signals are due to polarization of electron-hole pairs (POL) or due to electron or hole injection (ET or HT). B) Spectra show a negative voltage when electrons move away from the Kelvin probe and a positive voltage when electrons move towards the Kelvin Probe.

Figure 2. A) SEM and B) photograph of $550{ }^{\circ} \mathrm{C}$ annealed $\mathrm{Fe}_{2} \mathrm{O}_{3}$ nanorod array, showing the characteristic red color of hematite. C) XRD of annealed $\mathrm{Fe}_{2} \mathrm{O}_{3}$ film with reference pattern. D) Profilometer scan of hematite film on FTO after 24 hour hydrothermal synthesis.

Figure 3. Diffuse reflectance absorption and surface photovoltage spectra of $530 \pm$ $300 \mathrm{~nm}$ thick (24 hour reaction) $\mathrm{Fe}_{2} \mathrm{O}_{3}$ nanorod film on FTO in air atmosphere.

Figure 4. Photovoltage Spectra for $\mathrm{Fe}_{2} \mathrm{O}_{3}$ films with variable thickness.

Figure 5. Photovoltage of $\mathrm{Fe}_{2} \mathrm{O}_{3}$ film exposed to vacuum ( $\left.10^{-4} \mathrm{mbar}\right), 99 \% \mathrm{~N}_{2}, 99 \%$ $\mathrm{O}_{2}$, saturated $\mathrm{H}_{2} \mathrm{O}$ vapor in $\mathrm{N}_{2}$. Films were rinsed with water and dried in air before each scan.

Figure 6. Reversibility of photovoltage. A) Three repetitive SPV scans (every 24h) on a $\mathrm{Fe}_{2} \mathrm{O}_{3}$ film in air followed by one scan after rinsing with water. B) Photovoltage during long term on/off illumination cycle $(2.48 \mathrm{eV})$. C) Reversibility of photovoltage during on/off illumination cycle (continued from A).

Figure 7. A) Photovoltage in the presence of sacrificial electron donors. B) Photovoltage spectra as a function of $\mathrm{pH}$. $\mathrm{pH}$ was adjusted by soaking the $\mathrm{Fe}_{2} \mathrm{O}_{3}$ film in solutions of $\mathrm{NaOH}$ and $\mathrm{HCl}$.

Figure 8. Effects of surface modification with OER co-catalysts $\mathrm{Co}_{3} \mathrm{O}_{4}$ and $\mathrm{Co}-\mathrm{Pi}$ on the SPV spectrum. The data is for $0.1 \mathrm{M} \mathrm{Co}_{3} \mathrm{O}_{4}, 0.01 \mathrm{M} \mathrm{Co}_{3} \mathrm{O}_{4}$, unmodified, $15 \mathrm{~min}$ Co-Pi and 30 min Co-Pi deposition 
Figure 9. Energy diagram of $\mathrm{FTO} / \mathrm{Fe}_{2} \mathrm{O}_{3}$ system at $\mathrm{pH}=7$. For band assignments, compare to DFT calculations by Thimsen et al. ${ }^{55}$ The conduction band edge is based on Butler/Ginley calculation. ${ }^{56}$ No adjustment is made for surface charging because for $\mathrm{Fe}_{2} \mathrm{O}_{3}$ the $\mathrm{pH}_{\text {pzzp }}=8.5$ is close to 7.0. ${ }^{57}$

\section{References}

1. F. E. Osterloh, Top. Curr. Chem., 2015, DOI: 10.1007/128_2015_633

2. F. E. Osterloh, Chem. Soc. Rev., 2013, 42, 2294-2320.

3. N. Beermann, L. Vayssieres, S. E. Lindquist and A. Hagfeldt, J. Electrochem. Soc., 2000, 147, 2456-2461.

4. A. A. Tahir, K. G. U. Wijayantha, S. Saremi-Yarahmadi, M. Mazhar and V. McKee, Chem. Mater., 2009, 21, 3763-3772.

5. K. Sivula, R. Zboril, F. Le Formal, R. Robert, A. Weidenkaff, J. Tucek, J. Frydrych and M. Gratzel, J. Am. Chem. Soc., 2010 , 132, 7436-7444.

6. H. Dotan, K. Sivula, M. Gratzel, A. Rothschild and S. C. Warren, Energ. Environ. Sci., 2011, 4, 958-964.

7. K. Sivula, F. Le Formal and M. Gratzel, Chemsuschem, 2011, 4, 432-449.

8. J. Y. Kim, G. Magesh, D. H. Youn, J.-W. Jang, J. Kubota, K. Domen and J. S. Lee, Scientific Reports, 2013, 3, 2681.

9. L. Vayssieres, N. Beermann, S. E. Lindquist and A. Hagfeldt, Chem. Mater., 2001, 13, 233-235.

10. T. Lindgren, H. Wang, N. Beermann, L. Vayssieres, A. Hagfeldt and S.-E. Lindquist, Sol. Energ. Mat. Sol. C, 2002, 71, 231-243.

11. F. E. Osterloh, J. Phys. Chem. Lett., 2014, 5, 2510-2511.

12. J.-W. Jang, C. Du, Y. Ye, Y. Lin, X. Yao, J. Thorne, E. Liu, G. McMahon, J. Zhu, A. Javey, J. Guo and D. Wang, Nat. Commun., 2015, 6.

13. C. Du, X. G. Yang, M. T. Mayer, H. Hoyt, J. Xie, G. McMahon, G. Bischoping and D. W. Wang, Angew. Chem., Int. Ed. Engl., 2013, 52, 12692-12695.

14. R. L. Spray, K. J. McDonald and K.-S. Choi, The Journal of Physical Chemistry C, 2011, 115, 3497-3506.

15. S. A. Majumder and S. U. M. Khan, Int. J. Hydrogen Energy, 1994, 19, 881

16. A. Kay, I. Cesar and M. Grätzel, Journal of the American Chemical Society, 2006, 128, 15714-15721.

17. J. B. Gerken, J. G. McAlpin, J. Y. C. Chen, M. L. Rigsby, W. H. Casey, R. D. Britt and S. S. Stahl, J. Am. Chem. Soc., 2011, 133, 14431-14442.

18. L. Xi, P. D. Tran, S. Y. Chiam, P. S. Bassi, W. F. Mak, H. K. Mulmudi, S. K. Batabyal, J. Barber, J. S. C. Loo and L. H. Wong, J. Phys. Chem. C, 2012, 116, 13884-13889.

19. Y. Q. Liang, C. S. Enache and R. van de Krol, Int. J. Photoenergy, 2008, DOI: 10.1155/2008/739864.

$20 . \quad$ T. Hisatomi, J. Brillet, M. Cornuz, F. Le Formal, N. Tetreault, K. Sivula and M. Gratzel, Faraday Discuss., 2012, 155, 223232.

21. T. Hisatomi, H. Dotan, M. Stefik, K. Sivula, A. Rothschild, M. Gratzel and N. Mathews, Advanced Materials, 2012, 24, 26992702.

22. F. Le Formal, N. Tetreault, M. Cornuz, T. Moehl, M. Gratzel and K. Sivula, Chem. Sci., 2011, 2, 737-743.

$23 . \quad T$. Hisatomi, F. Le Formal, M. Cornuz, J. Brillet, N. Tetreault, K. Sivula and M. Gratzel, Energ. Environ. Sci., 2011, 4, 25122515.

24. R. L. Spray, K. J. McDonald and K.-S. Choi, J. Phys. Chem. C, 2011, 115, 3497-3506.

25. M. Barroso, A. J. Cowan, S. R. Pendlebury, M. Gratzel, D. R. Klug and J. R. Durrant, J. Am. Chem. Soc., 2011, 133, 1486814871 .

26. D. K. Zhong, S. Choi and D. R. Gamelin, J. Am. Chem. Soc., 2011, 133, 18370-18377.

27. J. E. Thorne, S. Li, C. Du, G. Qin and D. Wang, The Journal of Physical Chemistry Letters, 2015, 6, 4083-4088.

28. L. Kronik and Y. Shapira, Surf. Sci. Rep., 1999, 37, 1-206.

29. L. Kronik and Y. Shapira, Surf. Interface Anal., 2001, 31, 954965.

30. J. Lagowski, Surface Science, 1994, 299, 92-101.
31. J. Wang, J. Zhao and F. E. Osterloh, Energ. \& Envi. Sci., 2015 8, 2970-2976.

32. B. A. Nail, J. M. Fields, J. Zhao, J. Wang, M. J. Greaney, R. L. Brutchey and F. E. Osterloh, ACS Nano, 2015, 9, 5135-5142.

33. Y. Yang, J. Wang, J. Zhao, B. A. Nail, X. Yuan, Y. Guo and F. E. Osterloh, ACS Applied Materials \& Interfaces, 2015, 10, 5959-5964.

34. M. J. Greaney, E. Couderc, J. Zhao, B. A. Nail, M. Mecklenburg, W. Thornbury, F. E. Osterloh, S. E. Bradforth and R. L. Brutchey, Chem. Mater., 2015, 27, 744-756.

35. J. Wang and F. E. Osterloh, J. Mater. Chem. A, 2014, 2, 94059411.

36. J. Zhao and F. E. Osterloh, J. Phys. Chem. Lett, 2014, 5, 782786.

37. B. Klahr, S. Gimenez, F. Fabregat-Santiago, J. Bisquert and T. W. Hamann, Energ. Environ. Sci., 2012, 5, 7626-7636.

38. B. Klahr, S. Gimenez, F. Fabregat-Santiago, T. Hamann and J. Bisquert, J. Am. Chem. Soc., 2012, 134, 4294-4302.

39. C. Y. Cummings, F. Marken, L. M. Peter, K. G. U. Wijayantha and A. A. Tahir, J. Am. Chem. Soc., 2012, 134, 1228-1234.

40. J. Zhao and F. E. Osterloh, The Journal of Physical Chemistry Letters, 2014, DOI: 10.1021/jz500136h, 782-786.

41. L. Vayssieres, C. Sathe, S. M. Butorin, D. K. Shuh, J. Nordgren and J. H. Guo, Advanced Materials, 2005, 17, 23202323.

42. J. Kiwi and M. Gratzel, J. Chem. Soc. Farad. T. I, 1987, 83, 1101-1108.

43. Y. Cao, L. Jing, X. Shi, Y. Luan, J. R. Durrant, J. Tang and H. Fu, PCCP, 2012, 14, 8530-8536.

44. W. T. Sun, Q. Q. Meng, L. Q. Jing, D. N. Liu and Y. Cao, J. Phys. Chem. C, 2013, 117, 1358-1365.

45. B. Oregan, J. Moser, M. Anderson and M. Gratzel, J. Phys. Chem., 1990, 94, 8720-8726.

46. A. Duret and M. Gratzel, J. Phys. Chem. B, 2005, 109, 1718417191.

47. K. L. Hardee and A. J. Bard, J. Electrochem. Soc., 1976, 123, 1024-1026.

48. S. U. M. Khan and J. Akikusa, J. Phys. Chem. B, 1999, 103, 7184-7189.

49. H. Dau, C. Limberg, T. Reier, M. Risch, S. Roggan and P. Strasser, ChemCatChem, 2010, 2, 724-761.

50. A. Kay, I. Cesar and M. Gratzel, J. Am. Chem. Soc., 2006, 128, 15714-15721.

51. M. W. Kanan and D. G. Nocera, Science, 2008, 321, 1072 1075.

52. D. K. Zhong, M. Cornuz, K. Sivula, M. Graetzel and D. R. Gamelin, Energ. Environ. Sci., 2011, 4, 1759-1764.

53. J. Wang and F. E. Osterloh, Journal of Materials Chemistry A, 2014, 2, 9405-9411.

54. P. Vanysek, in CRC Handbook of Chemistry and Physics, CRC Press/Taylor and Francis, Boca Raton, FL, 88 (Internet Version 2008) edn., 2008.

55. E. Thimsen, S. Biswas, C. S. Lo and P. Biswas, J. Phys. Chem. C, 2009, 113, 2014-2021.

56. Y. Xu and M. A. A. Schoonen, Am. Mineral., 2000, 85, 543556.

57. M. A. Butler and D. S. Ginley, J. Electrochem. Soc., 1978, 125, 228-232. 
A)

Au Kelvin Probe $\boldsymbol{h} \boldsymbol{v}$

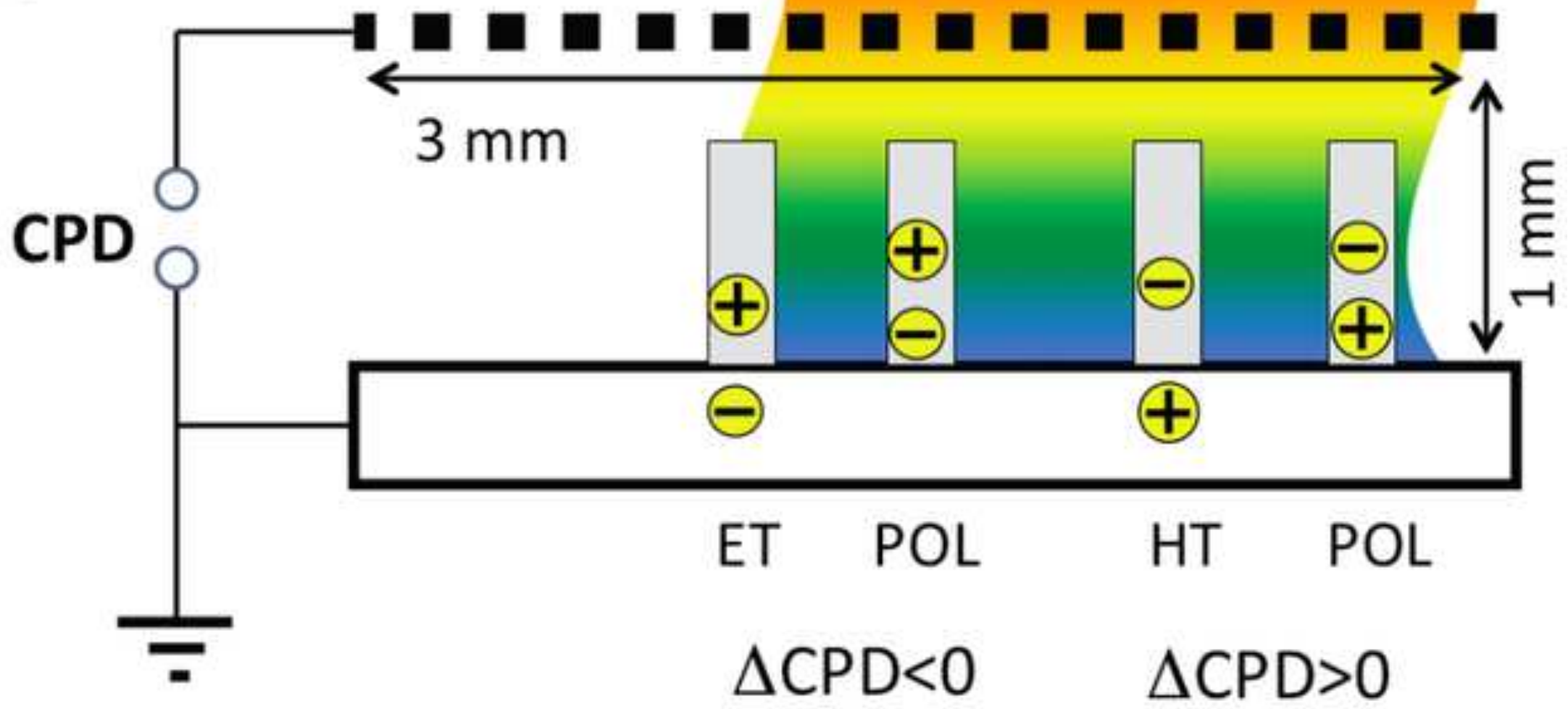

B)
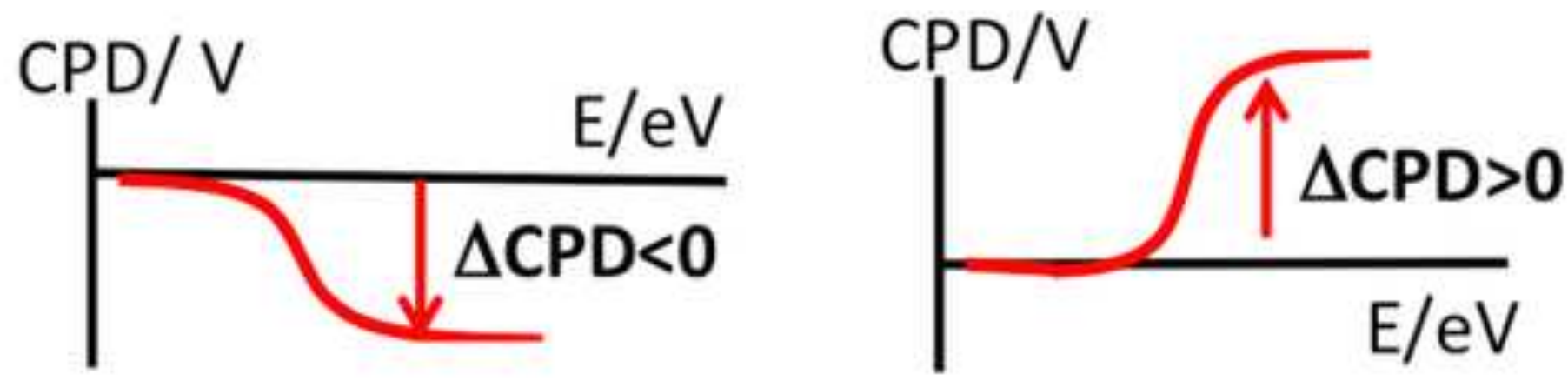

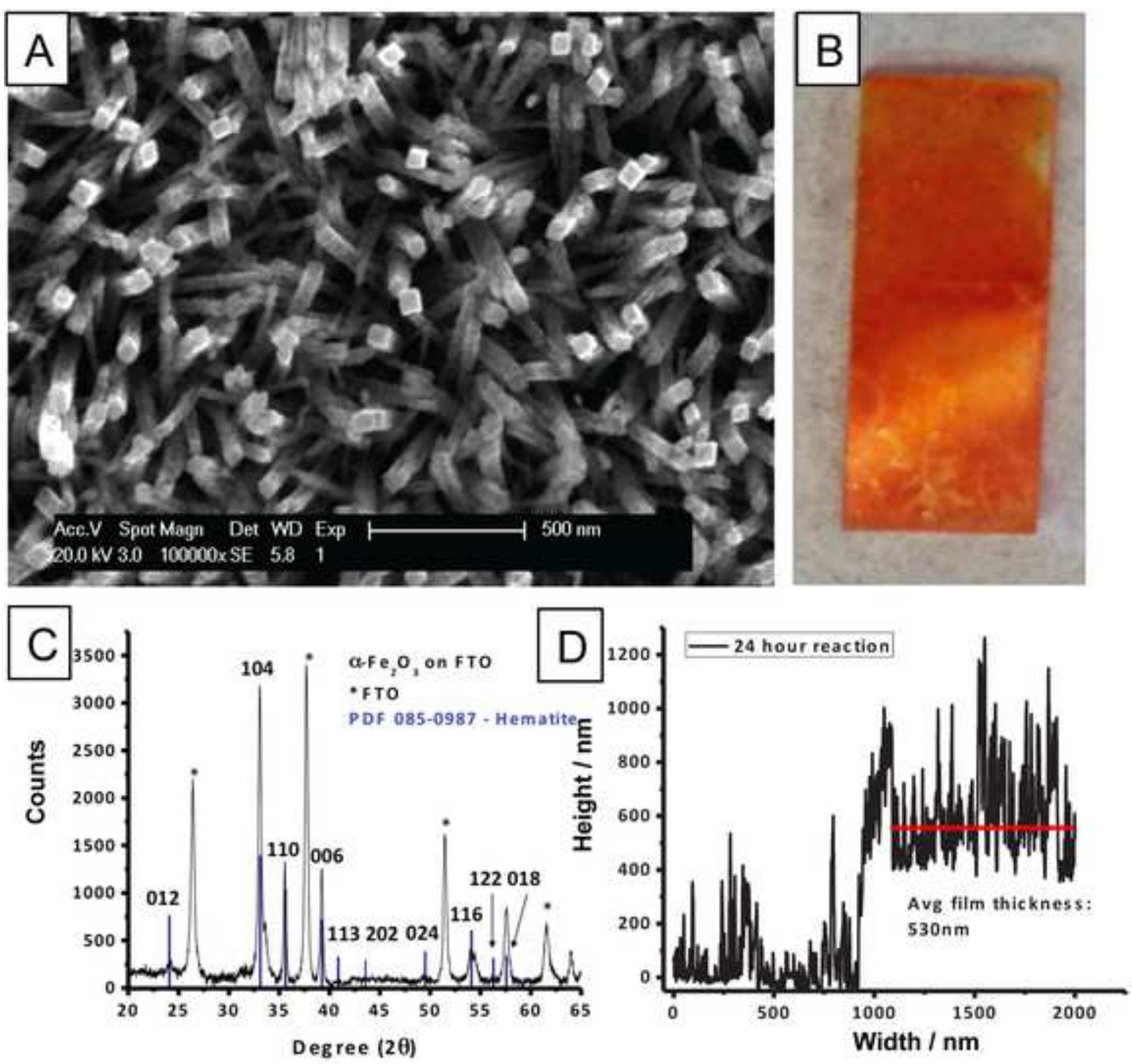


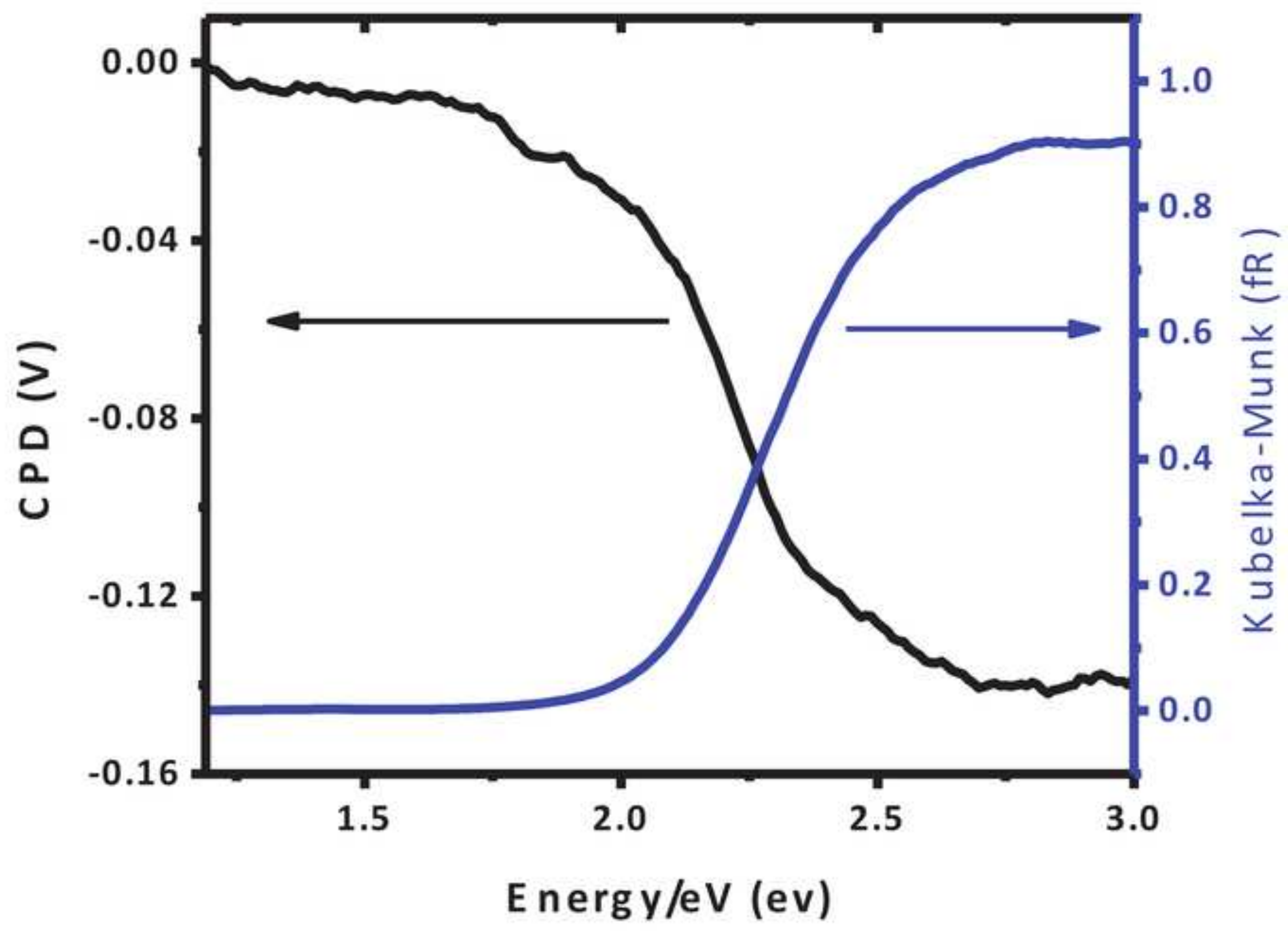




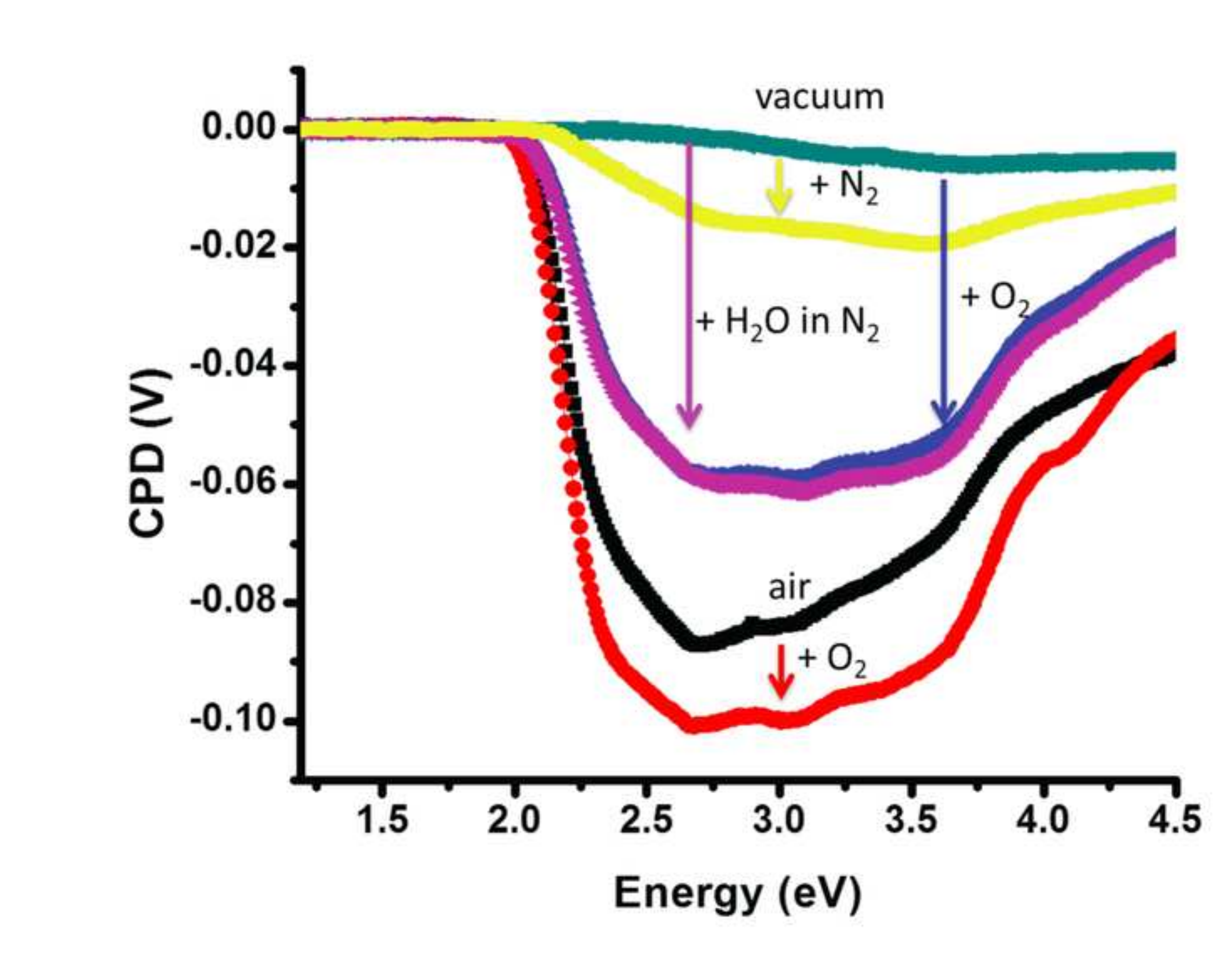

Energy (eV)

.

(2)

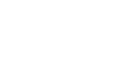

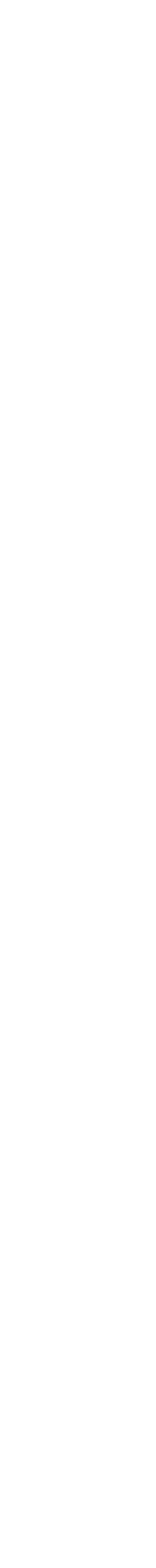

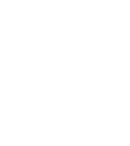

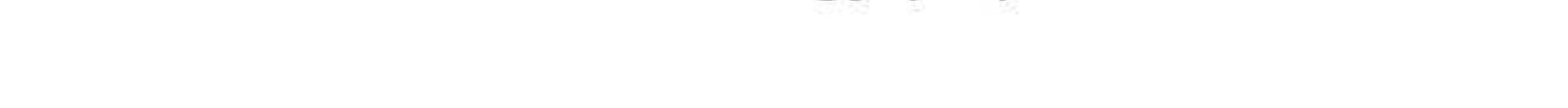



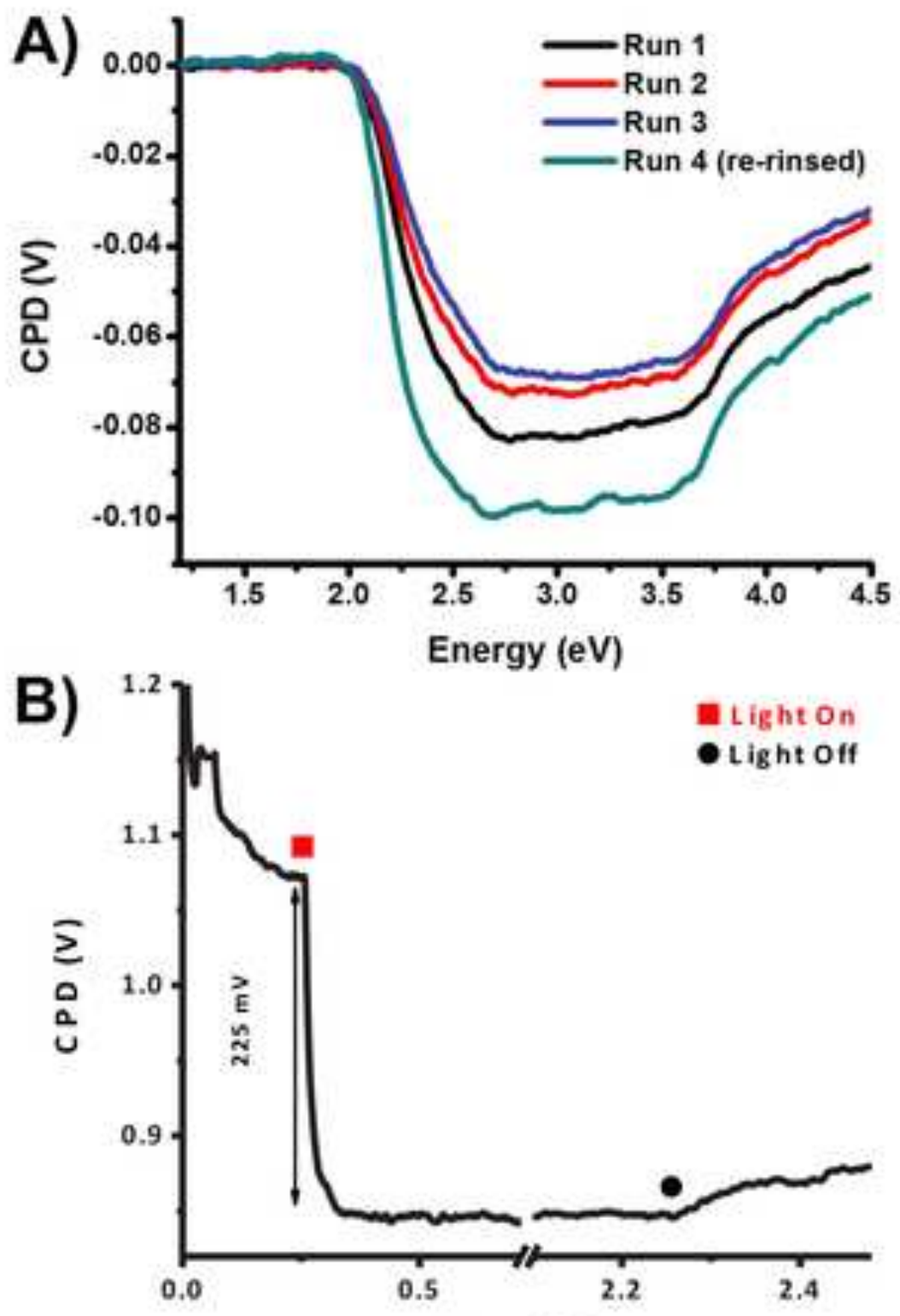

C)

Time (hr)

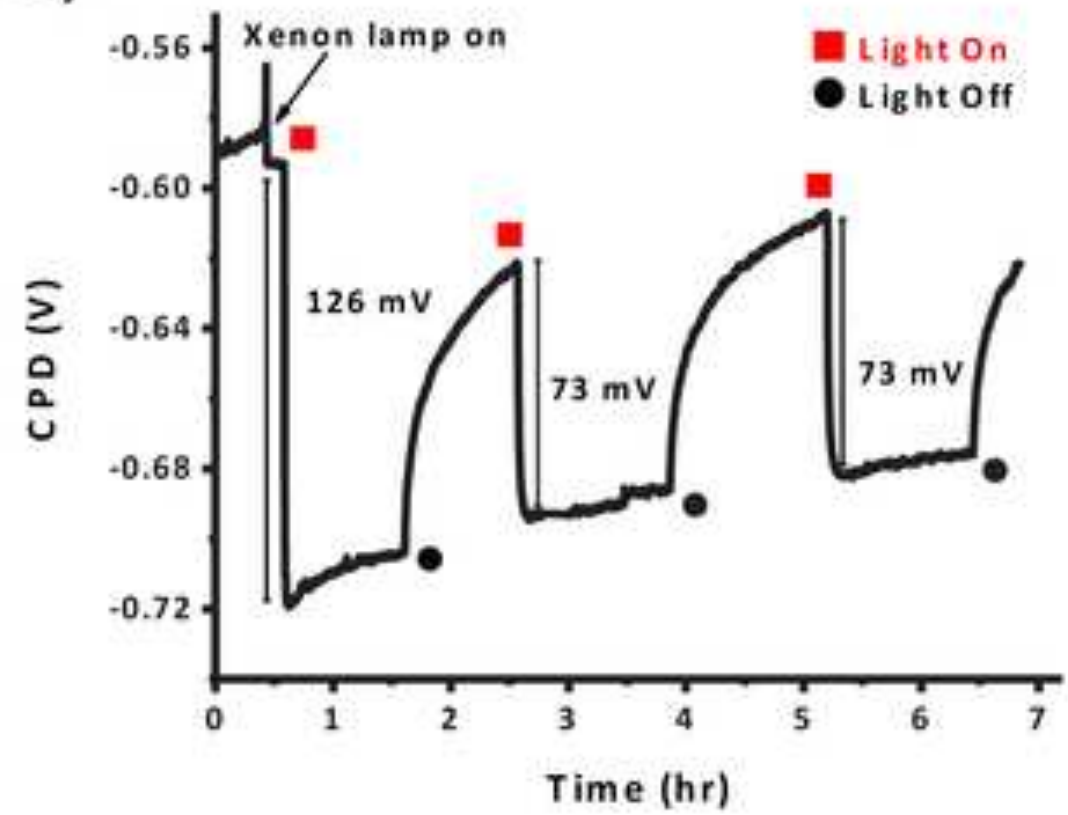

ne (hr) 


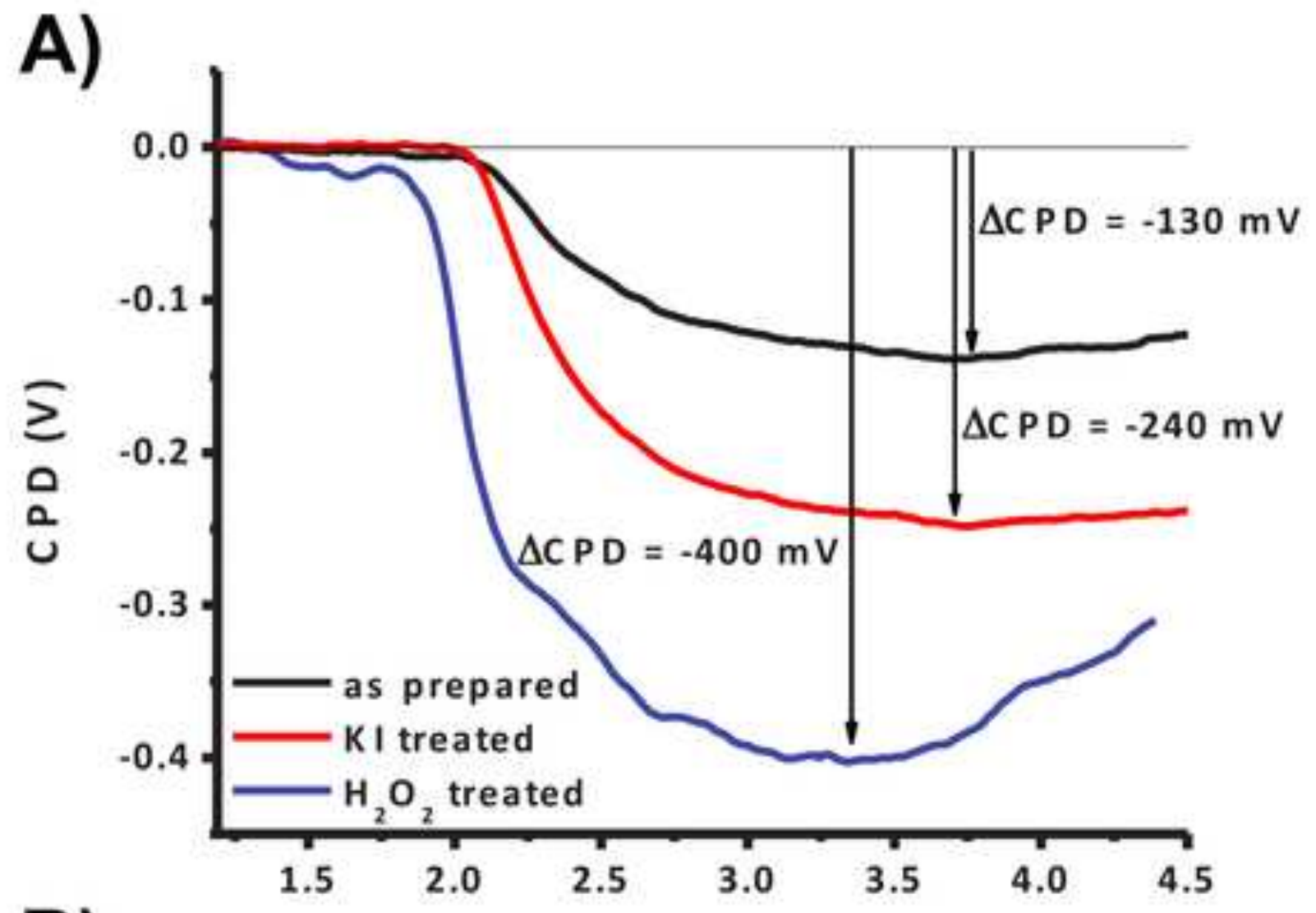

B)

Energy (eV)

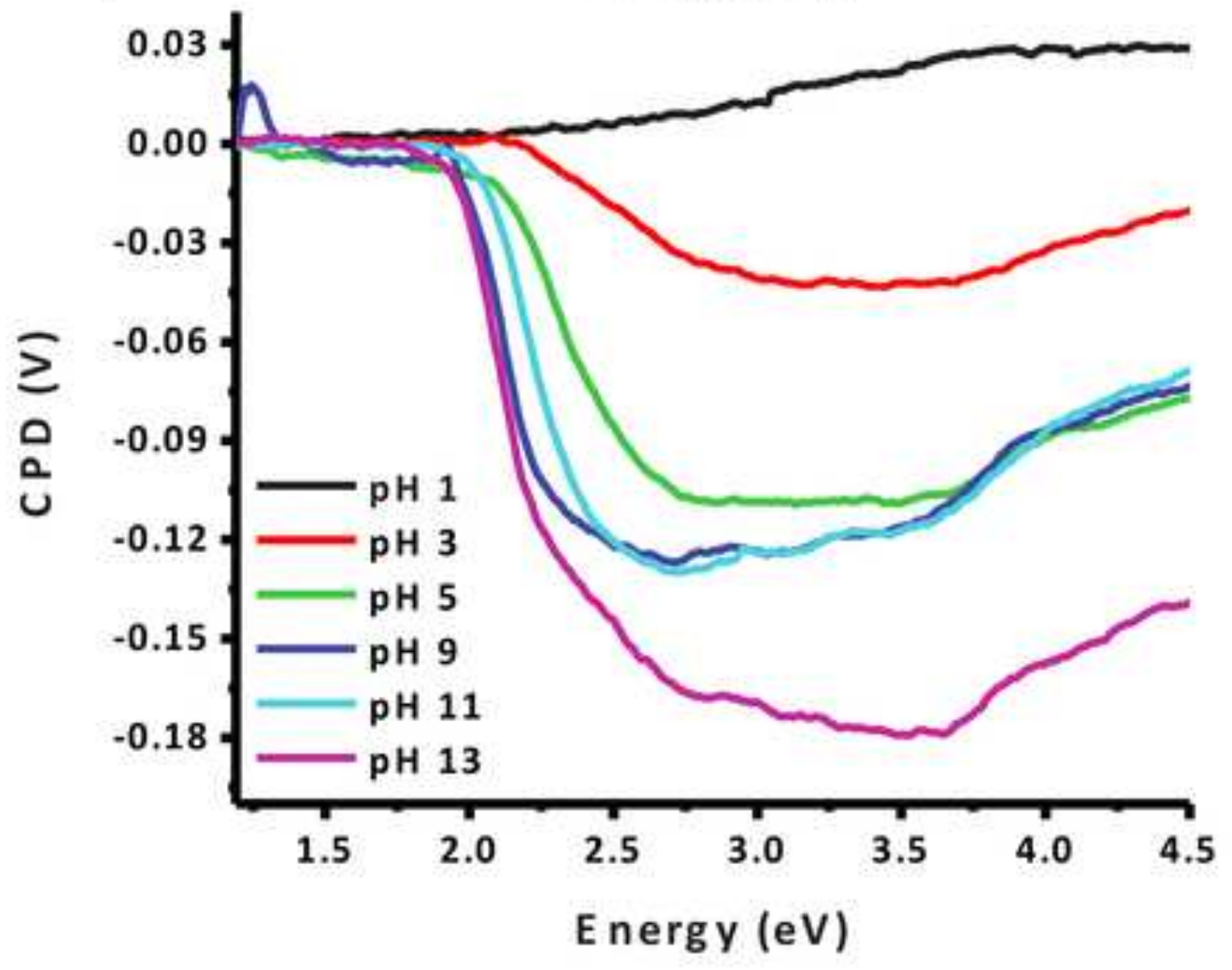




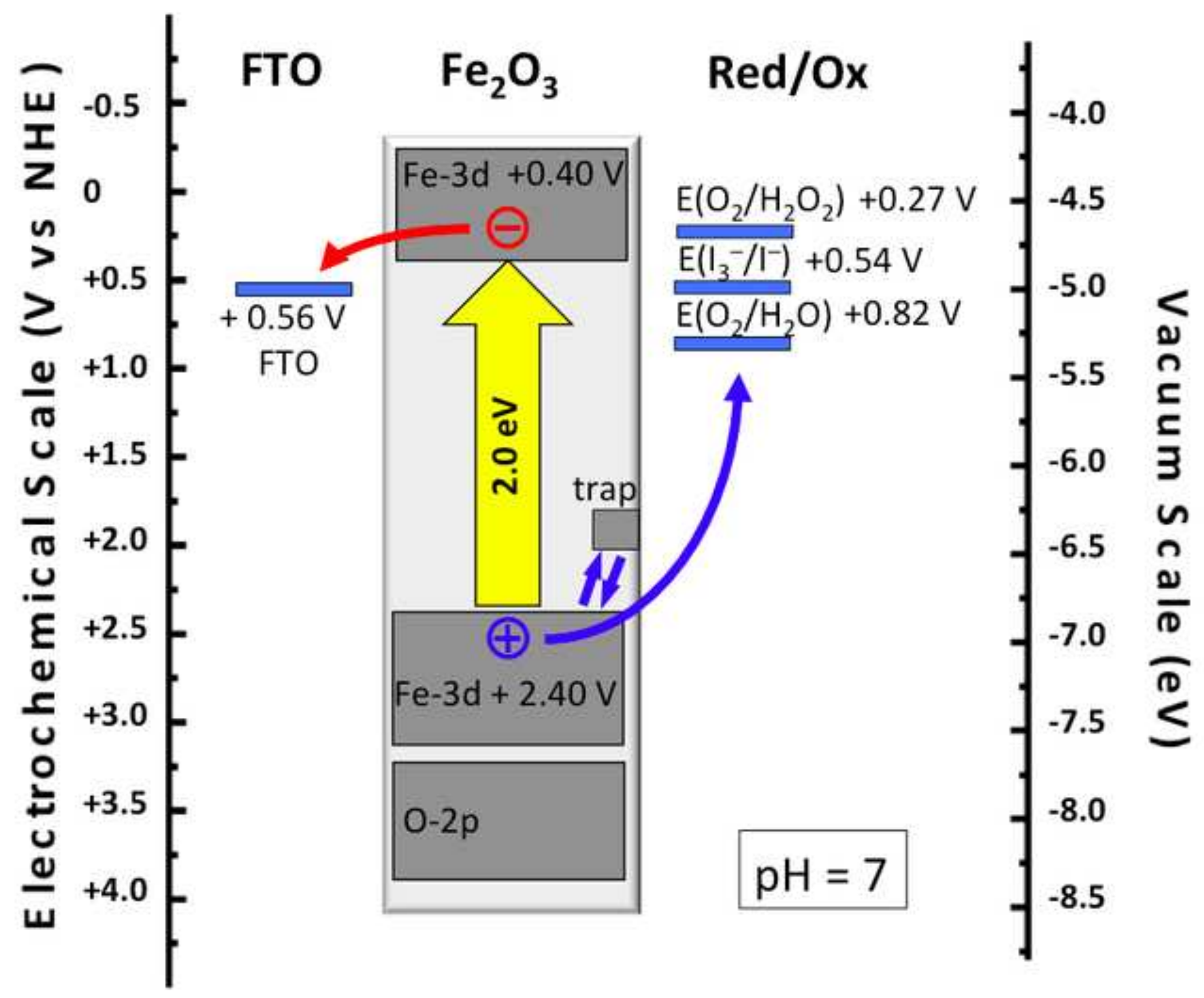


$+0.56 \mathrm{~V}$ FTO
Fe-3d +0.40 V

\section{$\mathrm{E}\left(\mathrm{O}_{2} / \mathrm{H}_{2} \mathrm{O}_{2}\right)+0.27 \mathrm{~V}$} $E\left(I_{3}{ }^{-} / I^{-}\right)+0.54 \mathrm{~V}$ $\mathrm{E}\left(\mathrm{O}_{2} / \mathrm{H}_{2} \mathrm{O}\right)+0.82 \mathrm{~V}$

$\mathrm{Fe}-3 \mathrm{~d}+2.40 \mathrm{~V}$

$$
0-2 p
$$

